\title{
Hemi-synthesis of novel (S)-carvone hydrazone from Carum carvi L. essential oils: Structural and crystal characterization, targeted bioassays and molecular docking on human protein kinase (CK2) and Epidermal Growth factor Kinase (EGFK)
}

\author{
Rima Tedjini ${ }^{\mathrm{a}, \mathrm{b}}$, Borhane E.C. Ziani ${ }^{\mathrm{c}}$, Teresa Casimiro ${ }^{\mathrm{b}}$, Raquel Viveiros ${ }^{\mathrm{b}}$, \\ Ricardo C. Calhelha ${ }^{\mathrm{e}}$, Lillian Barros ${ }^{\mathrm{e}}$, Leila Boukenna ${ }^{\mathrm{c}}$, Abderrezak Hamdi ${ }^{\mathrm{a}, *}$, \\ Redouane Chebout ${ }^{\mathrm{c}}$, Khaldoun Bachari ${ }^{c}$, Oualid Talhi ${ }^{\mathrm{c}, \mathrm{d}, *}$, Artur M.S. Silva ${ }^{\mathrm{d}}$ \\ ${ }^{a}$ Laboratory of Applied Organic Chemistry, Faculty of Chemistry, University of Science and Technology Houari Boumediene, BP 32, Alia Bab-Ezzouar, 16111 \\ Algiers, Algeria \\ ${ }^{\mathrm{b}}$ LAQV-REQUIMTE, Departamento de Química, Faculdade de Ciências e Tecnologia, Universidade NOVA De Lisboa,Caparica, 2829-516 Caparica, Portugal \\ ${ }^{c}$ Centre de Recherche Scientifique et Technique en Analyses Physico-Chimiques-CRAPC, BP384, Bou Ismail, Algeria \\ d QOPNA and LAQV-REQUIMTE, Department of Chemistry, University of Aveiro, 3810-193 Aveiro, Portugal \\ e Centro de Investigacão de Montanha (CIMO), Instituto Politecnico de Braganca, Campus de Santa Apolonia, 5300-253, Bragança, Portugal
}

\section{A R T I C L E I N F O}

\section{Article history:}

Received 5 April 2021

Revised 12 July 2021

Accepted 30 July 2021

Available online 1 August 2021

\section{Keywords:}

(s)-carvone hydrazone

Hemi-synthesis

2D NMR

Single-Crystal X-ray

Chiral HPLC

Cytotoxicity

Docking

\begin{abstract}
A B S T R A C T
Polyfunctional N,O,O,N-type ligands such as the oxalyl dihydrazide (ODH) may induce formation of mono, di-, and polynuclear complexes with natural monoterpene ketones, involving ligand bridging and Oxobridging. In this context, a novel chiral dihydrazone is designed through hemi-synthesis process by reacting oxalyldihydrazide $(\mathrm{ODH})$ with $(s)$-carvone, the major compound of caraway's seeds essential oil. The $C=N$ imine bi-condensation is performed without prior isolation of the natural $(s)$-carvone and the resulting $(s)$-carvone dihydrazone (s-CHD) is structurally characterized by Single-crystal X-ray diffraction, 2D-NMR spectroscopy and chiral LCMS analysis to confirm the formation of a single pure enantiomer. In-vitro cell-based assays were conducted on normal fibroblast (L929) using a presBlue (PB) fluorescence quantification method of cell-viability and by sulforhodamine B calorimetric cytotoxicity assays to determine the anti-proliferative effect on four human tumoral lines (NCI-H460, Hela, HepG2 and MCF-7) and normal PLP2. Anti-inflammatory assays were determined through NO production by Maurine LPS-stimulated macrophages (RAW 264.7). The (s)-CHD has no effect on normal cells viability (>88\%) and PLP2 $(\mathrm{GI} 50=326 \mathrm{ug} / \mathrm{mL})$, while a moderate $(\sim 55 \%)$ to significant $(\sim 63 \%)$ antigrowth potential was recorded against HepG2, Hela and MCF-7 tumor cell lines, where RAW 264.7 was feebly sensitive. A molecular docking was performed using Autodock vina software on the protein kinase CK2 and Epidermal Growth factor Kinase proteins EGFK and the dock scores allowed to identify significant binding affinities (lower $\Delta \mathrm{G}$ and Ki values) and potential hydrophilic/hydrophobic interactions with (s)-CHD comparing to the clinical ellipticine as potential ligands. Molecular docking suggests that $(s)$-CHD possesses high affinity towards the kinase domain receptors CK2 and EGFR, being able to bind to the ATP region.
\end{abstract}

(C) 2021 Published by Elsevier B.V.

\section{Introduction}

Plant terpenoids are extremely reactive secondary metabolites [1], of large structurally diverse configurations allowing them to be

\footnotetext{
* Corresponding author.

E-mail addresses: ahamdi_16@yahoo.fr (A. Hamdi), oualid.talhi@ua.pt (O. Talhi).
}

a molecular candidate for distinct hemi-synthesis processes [2-4]. Monocyclic terpenes and their derivatives are valuable molecules widely employed as pharmaceutical probes [1], where several scientific investigations pointed their structural importance to increase chemical properties and bioactivities of novel molecular scaffolds [5]. The chiral $(S)-()$-carvone (p-mentha-6,8-dien-2-one) is a monoterpene ketone naturally occurring in several plant essential oils (EOs) and has long been proved of no adverse ketone 
hazards [6]. The dextro $(d)$ form of carvone is mainly found in certain plant EOs, including Carum carvi L. (Apiaceae) and Zanthoxylum alatum DC. (Rutaceae) seeds [7-10], dill Anethum graveolens L. (Apiaceae) and fennel Foeniculum vulgare Mill. (Apiaceae) seeds [11], which are well documented in folk medicine for their remedies on gastric disorders [12,13]. Besides, the laevo $(l)$ form is the main constituent of spearmint EOs [11]. Reports [14] have showed that both enantiomers of carvone may be considered as starting materials for biologically active compounds. Previous studies highlighted several pharmacological effects of carvone and its derivatives as antimicrobial compound [15], antifungal [16], and antitumoral $[15,17,18]$. Different conventional methods, such as hydrodistillation [19], soxhlet [20] and supercritical fluid extraction [21], are used to extract EOs from $C$. carvi seeds, where reports usually highlighted large amounts of carvone (50-60\%) and limonene $(30-40 \%)$ in the volatile fraction [21,22]. Post-synthetic modification of (s)-carvone present in raw plant materials, by mean of its ketone function, may exhibit interesting biologically active compounds associated with a chiral interaction that plays a crucial role in the elaboration of synthetic or hemi-synthetic anticancer drugs $[23,24]$.

Distinguishably, recent scientific reports highlighted the possibility to convert aldehydes and ketones to hydrazone derivatives upon reaction with hydrazine $[25,26]$. Since hydrazines are more nucleophilic than simple amines due to the presence of the adjacent nitrogen, their condensation with carbonyl affords hydrazones in high yields, which are generally formed as a mixture of geometric isomers. Hemi-synthetic hydrazones issued from natural ketones and aldehydes can be further converted to their corresponding alkane via the Wolff-Kishner Reduction method [27]. Besides, the di-Schiff bases are polyfunctional N,O,O,N-type ligands which may form mono-, di-, and polynuclear complexes with monoterpene ketones [26,28] involving ligand bridging and oxobridging [29]. Thus, the possible $C=N$ imine condensation provided by hemi-synthesis processes may eventually allow access to more potent molecules that may exhibit a promising in vivo pharmacokinetic profile and other desirable biological properties. Additionally, the $(s)$-carvone was commonly used in hemisynthesis of a wide range of interesting molecules, particularly hydrazone derivatives with several interesting biological properties that are considered as important complexes for various pharmaceutical applications [30,31]. From a biological activity point of view, these novel structures may bind to several kinase inhibitors such as CK2 and EGFK offering powerful clinical activity with new insights on drug design. Previously, Prudent et al. [32] discussed the possibility of human protein kinase (CK2) inhibition by ellipticine as a novel mechanism involved in the tumoral growth inhibition. The authors reported that Cdk2-dependent p53 phosphorylation is selectively inhibited by ellipticine and 9hydroxyellipticine. The ellipticine derivatives have also inhibitory activity on the c-Kit, which is supposed to be an antiprolifirative agent.

Due to the outstanding chemical proprieties of the (S)-carvone and its potential reactivity, the current study reports an in-situ imine condensation of $C$. carvi seeds EOs with oxalyl dihydrazide (OHD) to obtain a new chiral (s)-carvone dihydrazone (s-CHD) structure via an hemi-synthetic approach. The resulting compounds was fully characterized by 2D-NMR, single crystal X-ray and chiral-LCMS. The novel s-CHD molecule was subjected to several bioassays that were screened in-vitro to determine its differential cytotoxicity proprieties in normal and tumor cell lines, as well as, its anti-inflammatory priorities through a down-regulation of NO production on LPS-simulated Maurine macrophages. Furthermore, the structure-activity-relationship (SAR) of a binary complex of protein kinase CK2 and ep interaction with our hemisynthesized s-CHD was studied using molecular docking.

\section{Results and discussion}

\subsection{Effect of extraction techniques on the chemical composition of the volatile oil}

We have first studied several extraction techniques of $C$. carvi seeds EOs and in order to optimize the extraction yield, Clevenger hydro-distillation (HD), soxhlet extraction (SE) and supercritical fluid extraction (SFE) were performed following the parameters set in Table 1. The extractions procedures were set based on the physicochemical proprieties of the targeted compounds and on the operating conditions of the extraction system. The influence of each extraction parameter was compared in terms of the visual aspect of the recovered oil and the extraction yields alongside to the major compounds' amount, particularly the (S)-carvone and limonene content (Table 1). The global yield was measured in triplicate then defined as a ratio (\%) of extracted oil mass ( $\mathrm{g}$ ) per plant dry seeds (g). Concomitantly, the chemical composition of the extracts was compared using GCMS analysis (See Supporting Information).

Initially, the visual appearance of the volatile fraction obtained from the three extraction processes was significantly distinct. The color of the oil obtained by conventional HD method was pale yellow, mostly approximating light-yellow liquid with a specific intense odor. However, the SE method provided an oil with a specific greenish-brown color, which was close to olive green color. The extracts recovered by the SFE technique had a brownish yellow color. The oil obtained from those latter techniques was semi-solid under ambient conditions $\left(22{ }^{\circ} \mathrm{C}\right.$ and $\left.0.1 \mathrm{MPa}\right)$ due to the presence of other high molecular weight compounds, which were found to be present in large amounts easily extractable with non-polar solvents (Hexane, supercritical $\mathrm{CO}_{2}$ ). While, the yield of extractable material obtained by the HD technique was significantly higher than the other two processes $3.85 \pm 0.7 \%$, followed by the SE and SFE extraction giving respectively $2.92 \pm 0.5 \%$ and $1.37 \pm 0.5 \%$, when using the whole plant material (integral seeds) and the ground material. Such differences in yield are probably related to the extraction parameters as previously highlighted by Assami et al., where the same extraction procedures have been undertaken by different parameters to extract the volatile fraction of $T$. articulata [33]. Chromatographic profiling has shown that the oil was characterized by a total of 58 compounds identified in HD extracts, 72 compounds in SFE extracts and 78 compounds in SE (See Supporting Information), which accounted for $93.71 \%, 98.62 \%$ and $98.5 \%$ of the total oil composition, respectively.

Herein, the study focuses on the major components identified by the above applied methods and more restricted to the amounts of $(S)$-carvone and $(R)$-limonene. The whole composition of the obtained EOs was profiled by a high presence of monoterpenoid ketones and cyclic monoterpenes. The major components identified in HD extracts were (S)-carvone (59.53\%) and (39.14\%) of limonene, being also highly present in SFE extracts at 9.39 to $31.32 \%$ for the $(s)$-carvone and 2.65 to $29.61 \%$ for limonene, for the integral and grinded seeds, respectively. Exceptionally, sabinene represented $34.46 \%$ in the oil obtained from SFE of the integrated seeds while $\beta$-Myrcene was considerably present in the oil obtained by SE and SFE. Additionally, for SE method, the $(s)$-carvone was present at $33 \%$, followed by the limonene at $23 \%$ and $p$-cymene $35.1 \%$. We noticed large differences concerning the nature and the extracted amounts of components according to the selected extraction process, which is found selective to certain compounds according to their physico-chemical proprieties such as solubility and diffusivity [34]. The same indications was discussed previously [35] in relation to the extraction procedure, that highlighted a variation in the separated amounts of molecules. Noticeably, when operating SFE, a change of the extraction temperature in the extractor 
Table 1

The extraction conditions, total yield, and major compounds amounts of $C$. carvi volatile fraction.

\begin{tabular}{lllll}
\hline & \multirow{2}{*}{ Procedure } & Hydrodistillation & Soxhlet Extraction & \multicolumn{2}{l}{ Supercritical Fluid } \\
\cline { 4 - 5 } & & & All Seeds & Grinded seeds \\
\hline Solvent & Water & Hexane & $\mathrm{CO}_{2}$ & $\mathrm{CO}_{2}$ \\
Temperature $\left({ }^{\circ} \mathrm{C}\right)$ & $100 \pm 0.5$ & $70 \pm 5$ & $35 \pm 1$ & $35 \pm 1$ \\
Pression (Bar) & - & - & 125 & 125 \\
Flow (ml/min) & - & - & 4 & 4 \\
\hline Oil aspect & pale yellow & greenish-brown & brownish-yellow & brownish-yellow \\
\hline Yield $(\%)$ & $3.85 \pm 0.7$ & $2.92 \pm 0.5$ & $1.37 \pm 0.5$ & $1.37 \pm 0.5$ \\
$(S)$-carvone $(\%)$ & 59,53 & 32,99 & 38,62 & 40,09 \\
$(R)$-limonene $(\%)$ & 39,134 & 23,03 & 2,65 & 29,61 \\
\hline
\end{tabular}

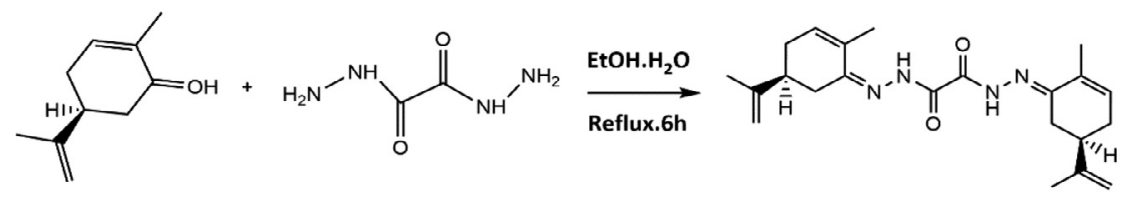<smiles>C=C(C)[C@@H]1CC=C(C)[C@](O)(CC)C1</smiles>

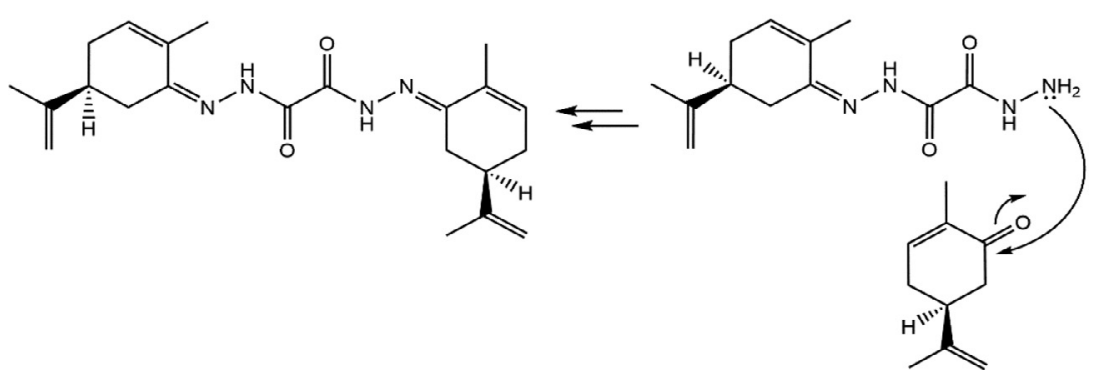

Scheme 1. The reactional mechanism Synthesis reaction of a (S)-carvone hydrazone.

has considerable effect on the chemical composition of the extracts and the temperature of $40{ }^{\circ} \mathrm{C}$ seems to be an optimal condition. Authors supports the use of innovative processes such as SFE over HD to target selective extraction toward certain types of molecules in shorter time and at lower temperature as main advantages [36]. Therefore, previous reports [37] reveled that SFE appears to be the optimum process for obtaining volatile oil of high quality with a good yield.

\section{2. (s)-carvone dihydrazone ( $(\mathrm{s}-\mathrm{CHD})$ synthesis and chemical characterization}

The hemi-synthesis of (S)-CHD from natural starting material, has been achieved by a simple imine bi-condensation reaction of (s)-carvone as the major component of the caraway seeds EOs with oxalyl dihydrazide without any prior purification or isolation from the oil matrix. The reactional mechanism is described in Scheme 1 and the final product (S)-CHD is formed with high purity at $82.5 \%$ yield. The existence of several different potential $\mathrm{H}$-bond donor/Hbond acceptor groups in the ODH molecule, alongside to the possible adopted orientations of the $\mathrm{N}-\mathrm{H}$ bonds of the amine $\mathrm{NH}_{2}$ groups with respect to the molecule median plan, leads to several possible geometric conformations and $\mathrm{H}$-bonding arrangements favorable to connect to monoterpenic ketones through $C=N$ crosscoupling. Moreover, ODH is a polymorph which may exist in a number of different energetically accessible conformations with respect to the orientations of the terminal $\mathrm{NH}_{2}$ groups [26,29].

The rotation of the amine $\mathrm{NH}_{2}$ group around the $\mathrm{NH}-\mathrm{NH}_{2}$ bond is associated with a relatively low energy barrier, and thus a range of different conformations of the $\mathrm{NH}-\mathrm{NH}_{2}$ end groups should be accessible for the $(s)$-carvone. To the authors knowledge, the final compound (S)-CHD was not reported in the literature and possesses an asymmetric structure since the reaction was carried out over the (s)-carvone carbonyl group, ultimately maintaining the configuration of the asymmetric center of (s)-carvone. Accordingly, the structural elucidation of the synthetized compound was carried out by mass spectrometry and elemental analysis. Basically, the positive-ion API-ES spectrum showed only one peak at $m / z 383.2$ (100\%) (See Supporting Information), thus, the molecular-ion peak is compatible with the molecular formula $\mathrm{C}_{22} \mathrm{H}_{30} \mathrm{~N}_{4} \mathrm{O}_{2}(M+H)$, which was further confirmed by elemental analysis C: $66.47 \%$; $\mathrm{H}$ : 7.62; N: $15.67 \%$. 


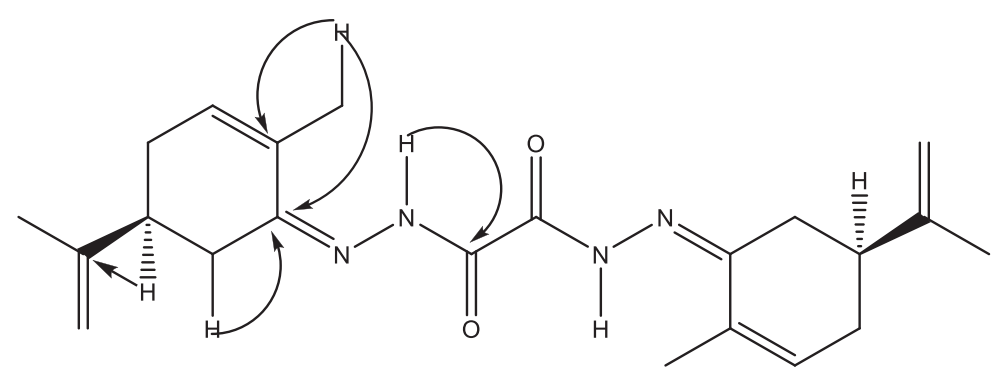

Fig. 1. (HMBC 1H/13C 2D NMR correlations of (s)-CHD.

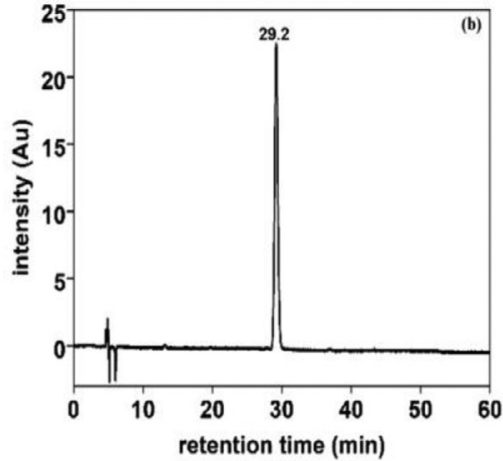

(a)

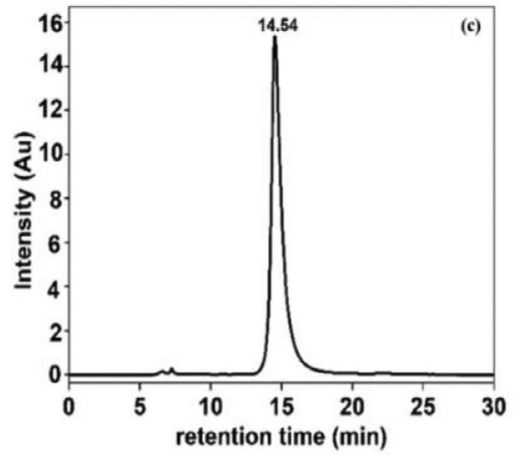

(b)

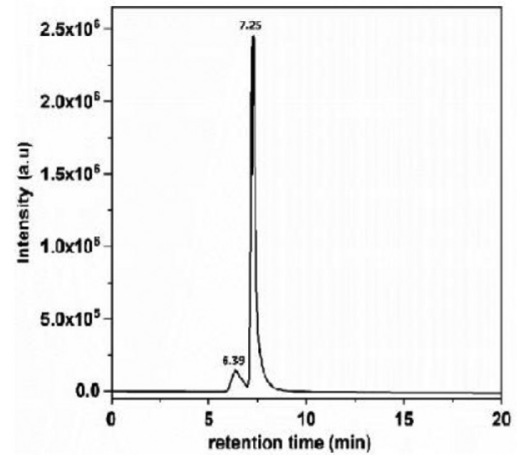

(c)

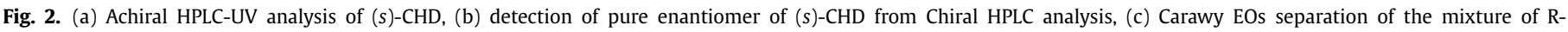
limonene and S-carvone.

NMR spectra of caraway seeds EOs confirmed the presence of a mixture of carvone and limonene as major compounds by comparison to their standard ${ }^{1} \mathrm{H}$ NMR spectra (See Supporting Information). Interestingly, ${ }^{1} \mathrm{H}$ NMR spectrum of (S)-CHD displayed new signals appearing at $\delta=10.86-11.14 \mathrm{ppm}$, being assigned to the functional amine group from $\mathrm{ODH}$, confirming therefore the formation of the hydrazone (S)-CHD. Further information can be obtained from $\mathrm{HMBC} 1 \mathrm{H} /{ }^{13} \mathrm{C}$ 2D NMR spectrum, where $\mathrm{NH}$ entertains correlation with the carbonyl function; $2-\mathrm{CH}_{3}$ shows both correlations with the imine $C=N$ carbon and $C=C$ intracyclic double bond. Other important $\mathrm{HMBC}$ connectivities are illustrated in Fig. 1. Additionally, duplication of some proton signals, such as those of the amine function and methyl groups is a sign of having asymmetrical conformations present in solution.

Accordingly, the synthesized molecule (S)-CHD was analyzed by liquid chromatography using an HPLC C18 reversed-phase (UVdetection at wavelength $254 \mathrm{~nm}$, eluent and sample solvent: acetonitrile/water $70: 30 \mathrm{v} / \mathrm{v}$, injected volume of $20 \mu \mathrm{l})$, where the LC chromatogram (Fig. 2) showed the presence of one sharp peak, indicating a high purity of the product without any possible interferences being formed within the matrix. Additionally, a similar LC profile of (S)-CHD was obtained from chiral HPLC separation, which proved the existence of pure enantiomer appearing as a unique peak at a distinct retention time (14.54 min) comparing to those recorded for the mixture of R-limonene and S-carvone (at $6.39 \mathrm{~min}$ and $7.25 \mathrm{~min}$, respectively) from the caraway EOs Chiral HPLC analysis (Fig. 2). This finding confirms the formation of a single chiral core without any impurities originating from traces essential oil waste.

The X-ray diffraction studies reveal that the (s)-CHD is comprised of enantiomorphic triclinic P1 space group with the asymmetric unit having only one molecule exhibiting (S)-configuration (Fig. 3). Although, the crystal structure displays a pseudo center of symmetry element with $89 \%$ fit, tests with PLATON/ADDSYM [38], revealed the existence of pseudo-translations, but no obvious need for a space group change. LEPAGE cell symmetry tools also indicated no alternative metrical symmetry found. All non-hydrogen atoms were refined anisotropically and the hydrogen atoms were inserted in idealized positions and allowed to refine riding on the parent carbon atom. In addition, using the natural source ( $s$ carvone as a starting chiral reagent implying that the product obtained was crystallized in chiral and asymmetric space group. The asymmetric unit presents hydrogen bonds interactions, which are described in Fig. 3 [39]. Moreover, the comparison of the experimental powder diffraction pattern with the theoretically predicted using data from single crystal diffraction were proved that the resulting compound represent the bulk of the product obtained, thus assuring the homogeneity of the synthesized compound in 95\% yield (See Supporting Information).

\subsection{Bioactivities evaluation}

Cell-based viability assays enables monitoring cytotoxic events in populations of cells exposed to a new synthesized molecule [40]. First, the normal L292 fibroblasts cells viability was monitored through the evaluation of viable cell levels exposed to a concentrations range of $(s)$-CHD in aqueous solutions as summarized in Table 2. The (s)-CHD has been shown to have slight effect on normal cell growth that was not a dose-dependent manner. The representative dose-response survival values indicated that at the lowest molar concentration $(0.7 \mu \mathrm{M}), 90 \%$ of viability was recorded, while at the highest concentration $(100 \mu \mathrm{M})$ a high viability rate $(82 \%)$ was either obtained. Tehrani et al., reported the same behavior of the hydrazine and arylhydrazone derivatives on fibroblast L929 cells that remain viable even at higher concentrations [41]. These results showed the suitability to investigate the cytotoxicity of the synthesized (s)-CHD on tumoral lines. On the other hand, the growth inhibitory effect of the (s)-CHD on four 


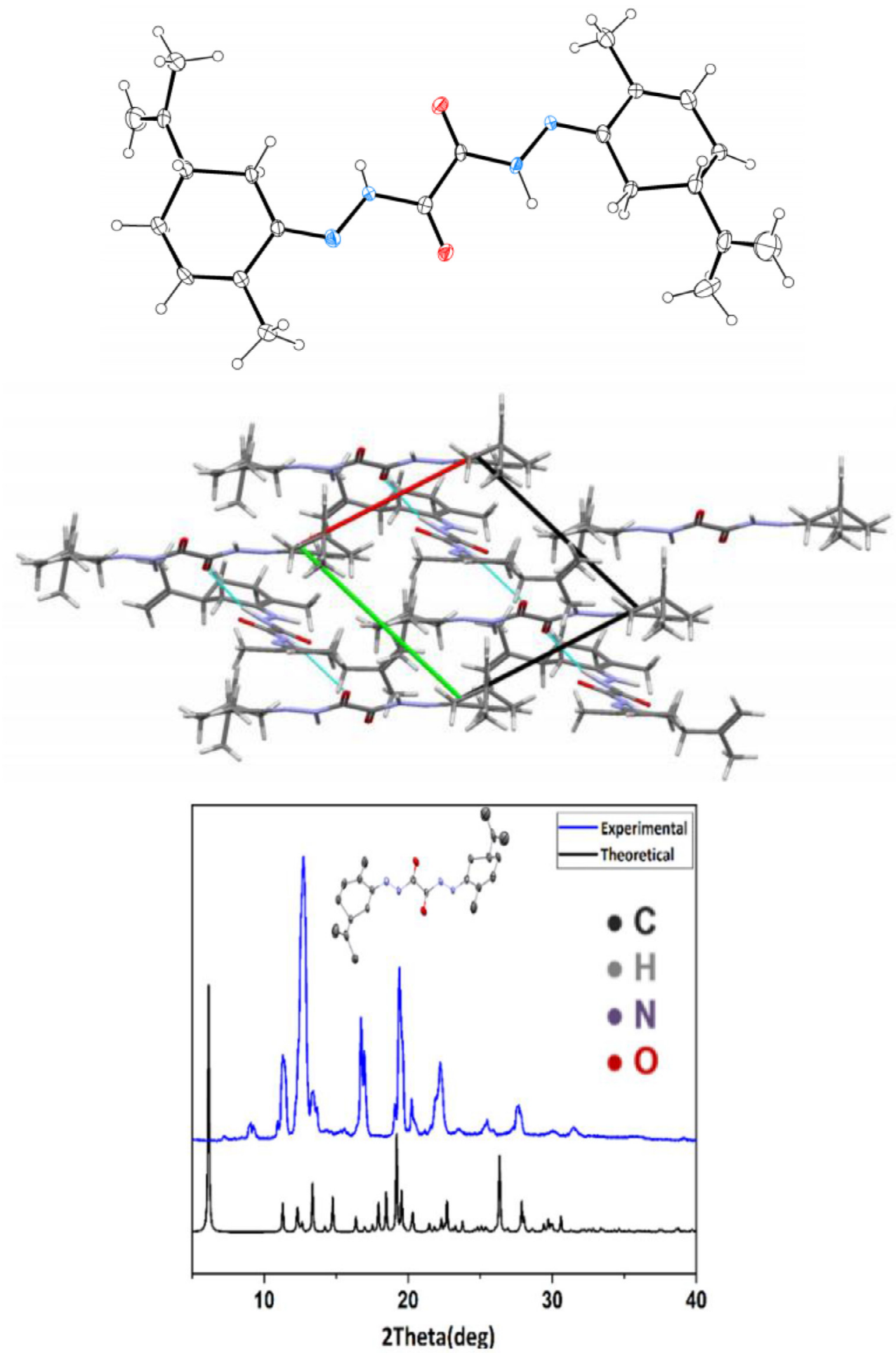

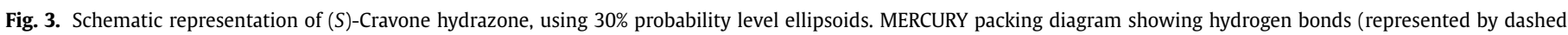
light-blue lines), viewed along the $\mathrm{c}$ axis and X-ray powder diffraction of $(s)$-CHD comparing with the experimental pattern was predicted using data from SCXRD.

human tumor cell lines (NCI-H460, Hela, HepG2 and MCF-7) and normal PLP2 was evaluated in-vitro using Sulforhodamine B colorimetric assay and the results were expressed in GI50 as summarized in Table 2.

Ellipticine, a clinically used antitumor agent was also evaluated as a positive control. The tumoral cells response towards (s)-CHD was from a moderate to significative inhibition of cell proliferation being specially active against Hela, MCF-7 and HepG2 that exhibited equipotent activity as evidenced by a lower $\mathrm{GI}_{50}$ values of
$150.6 \pm 7.4 \mu \mathrm{g} / \mathrm{mL}, 176.9 \pm 7.6 \mu \mathrm{g} / \mathrm{mL}$ and $178.9 \pm 6.4 \mu \mathrm{g} / \mathrm{mL}$ respectively. In contrast, the ellipticine was far more effective recording a high antigrowth potency depicted through lower $\mathrm{GI}_{50}$ value $(<2 \mu \mathrm{g} / \mathrm{mL}$ ) against all cells line. Interestingly, the normal PLP2 cells growth was poorly affected by (s)-CHD with higher $\mathrm{GI}_{50}$ of $325.9 \pm 11.2 \mu \mathrm{g} / \mathrm{mL}$. Thus, it was noticed through the obtained results that the ( $s$-CHD exhibited a selective potency against Hela, MCF-7 and HepG2 cells compared to the conventional chemotherapeutic drug (ellipticine) that affected the growth of all the cell 
Table 2

Cell viability, cytotoxicity against tumoral lines and anti-inflammatory assays of (S)-carvone hydrazone.

\begin{tabular}{|c|c|c|c|c|c|c|c|c|c|}
\hline \multicolumn{10}{|c|}{ Cell viability } \\
\hline Concentration $(\mu \mathrm{M})$ & $\mathbf{0}$ & 0.7 & 1.5 & 3 & 6 & 12 & 25 & 50 & 100 \\
\hline Viability* (\%) & 100 & $90 \pm 4.1$ & $94 \pm 2.1$ & $93 \pm 3.2$ & $92 \pm 3.2$ & $93 \pm 1.5$ & $91 \pm 4.1$ & $88 \pm 7.2$ & $82 \pm 1.6$ \\
\hline \multirow[t]{4}{*}{ Growth inhibition values $\left(\mathrm{GI}_{50}, \mu \mathrm{g} / \mathrm{mL}\right)$} & \multicolumn{4}{|c|}{ Cell lines } & \multicolumn{3}{|l|}{ (s)-CHD } & \multicolumn{2}{|l|}{ Ellipticine } \\
\hline & \multicolumn{4}{|c|}{ NCI-H460 } & \multicolumn{3}{|c|}{$188.9 \pm 7.4$} & \multicolumn{2}{|c|}{$1.03 \pm 0.09$} \\
\hline & \multicolumn{4}{|c|}{ Hela } & \multicolumn{3}{|c|}{$150.6 \pm 7.4$} & \multicolumn{2}{|c|}{$1.91 \pm 0.06$} \\
\hline & \multicolumn{4}{|c|}{ PLP2 } & \multicolumn{3}{|c|}{$325.9 \pm 11.2$} & \multicolumn{2}{|c|}{$3.2 \pm 0.7$} \\
\hline \multicolumn{10}{|c|}{ Anti-inflammatory } \\
\hline Nitric oxide NO. production $\left(\mathrm{IC}_{50}, \mu \mathrm{g} / \mathrm{mL}\right)$ & \multicolumn{4}{|c|}{ RAW 264.7} & \multicolumn{3}{|l|}{ (s)-CHD } & \multicolumn{2}{|c|}{ Dexamethasone } \\
\hline & & & & & \multicolumn{3}{|c|}{$222.3 \pm 4.1$} & \multicolumn{2}{|l|}{$16 \pm 1$} \\
\hline
\end{tabular}

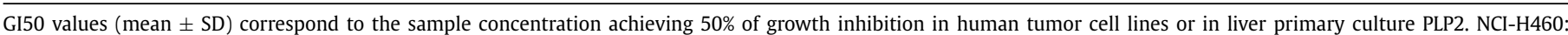

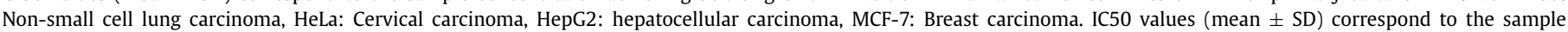

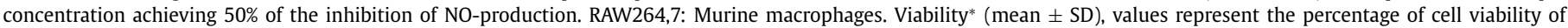
the synthesized (S)-carvone hydrazone with respect to $100 \%$ control according to molar concentration.

lines even the normal PLP2 cells. This behavior may be contrasted with the structural configuration of the $(s)$-CHD that may interact specifically with certain protein receptors involved in tumoral growth processes. Accordingly, the observed cytotoxic effects may be partially attributed to the $\mathrm{NH}$ proton and the carbonyl group reactivity that enable a significant antiproliferative activity through complexation with cell's DNA or proteins such protein kinase CK2 and epidermal growth factor kinase, that are involved in tumoral cell growth, cell differentiation, apoptosis and oncogenic transformation [42,43]. Previously, Golla et al., [44] reported that a succinohydrazone derivative, where the structure is close to the $(s)$ CHD, conferred higher cytotoxicity against human breast adenocarcinoma cells (MDA-MB-231) and was non effective against human cervical carcinoma (HeLa) and human lung carcinoma (A549) cells. Furthermore, the anti-inflammatory results were recorded on the NO levels for the LPS-stimulated RAW 264.7. The LPS stimulation polarizes macrophages toward the M1 phenotype, which is characterized by the production of high levels of pro-inflammatory cytokines, inducing production of nitric oxide (NO) [45]. The response of the cells exposed to the (s)-CHD were less sensitive (high $\mathrm{IC}_{50}$ intermediate response), with a persistent formation of NO during the inflammatory process. The (s)-CHD could partially down regulate NO production comparatively to the dexamethasone with higher anti-inflammatory potential used as positive control.

\subsection{Molecular docking}

Since CK2 and EGFR expression are involved in tumoral cells growth and proliferation $[42,43]$, their possible inhibition is seen as a promising approach for innovative therapeutic strategies in cancer treatment. In order to test whether the designed molecule (s)-CHD could inhibit the ligand binding-induced receptor, a virtual molecular docking was performed on research hypothesis considering the recorded cytotoxic potential using Autodock vina software. The docking scores of the binding affinity $(\Delta G)$, root mean square deviation (RMSD), inhibition constant (Ki) and the intermolecular interactions of (s)-CHD and the standard ellipticine with the ATP binding pocket of the CK2 and EGFRK receptors are presented in Table 3. For ellipticine, the molecular docking was performed on the basis of its binding energy and overlay methods, which should confirm the possible similarities in binding patterns that may occur with the (s)-CHD. Autodock vina scores makes clear that the (s)-CHD has a significant $\mathbf{\Delta G}$ values of $-9.4(\mathrm{Ki}=0.127 \mu \mathrm{m})$ and $-8.3 \mathrm{Kcal} / \mathrm{Mol}(\mathrm{ki}=0.812 \mu \mathrm{m})$ with $\mathrm{CK} 2$ and EGFK binding sites respectively. The designed molecule was found to bind on the same binding site with the ellipticine that exhibited close interaction scores on the same receptors (CK2, $\Delta \mathrm{G}=-8.3 \mathrm{Kcal} / \mathrm{Mol}$, $\mathrm{ki}=0.02 \mu \mathrm{m}$; EGFK, $\Delta \mathrm{G}=-8.5 \mathrm{Kcal} / \mathrm{Mol}, \mathrm{ki}=0.579 \mu \mathrm{m})$. This interaction affinity is due to the existence of potential $\mathrm{H}$-bond donor and H-bond acceptor groups as well as the hydrophobic interactions with the docked molecules. For the (s)-CHD, the $N-H$ bonds of the secondary amine and the oxygen atom of the carbonyl group $C=O$ may adopt different orientations [26]. A possible geometric permutation for hydrogen-bonding arrangements are formed in two site point interactions (H-bonds) of less than $3 \AA$ length with the binding site residue of ASN118:HD22 (2.6 $⿱$ ) and HIS160:HE2 $(2.31 \AA)$ residue for $\mathrm{CK} 2$ and three strong conventional $\mathrm{H}$-bond with ASP831:OD residue (2.13 to $2.97 \AA$ ) for EGFK (Fig. 4). The observed hydrogen bonds in the (S)-CHD demonstrate the importance of the amine moiety and $C=O$ groups in this intermolecular interaction of receptor's pocket. It was also noticed that hydrophobic interactions were formed between the (s)-CHD and CK2 involving mainly the residues VAL53, VAL66, MET163, ILE 174 and HIS160 due to an electron-donating groups on the (S)-CHD phenyl rings that increase the electron density. For instance, in the case of CK2, the $(S)$-CHD is further stabilized by the external side of the ATP pocket by the mean of $\pi$-interaction between its phenyl ring and histidine at position 160 (Fig. 4). Besides, the perillalkyl groups and the phenyl rings of the (S)-CHD were positioned in a way that can fit deep into the hydrophobic pocket of CK2 and EGFR. The introduction of electron-donating groups ( $\pi$-electron donating) on the phenyl ring increases the electron density, thereby enhancing the interaction with the chosen receptors. In the case of the EGFR, $(S)$ CHD adopted interesting electrostatic interaction (salt bridge) between positive NH groups and Negative ASP831:OD1 (2.39 $\AA$ ) and ASP831:OD1:B (2.97 $\AA$ ). Similarly, an interesting pose was set on the phenyl ring and extended towards the entrance of the receptor binding site and formed $\pi$-alky/ $\pi$-orbitals interaction with Phe699 (4.94 А).

Ellipticine on the other hand, has shown similar binding conformation with negative higher values of $\Delta G$, the carbazole moiety forming parallel displaced T-shape and $\pi$-stacking interactions with HIS160 and PHE113 in the case of CK2 and formed $\pi-\sigma$ and $\pi$-sulfur interaction, respectively, with VAL702:CG1,2,3 and MET742 residues in the EGFK ATP pocket. In the predicted binding orientation, the standard ellipticine exhibited a hydrogen bond 
Table 3

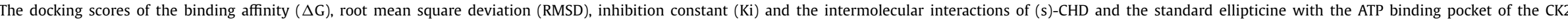
and EGFRK receptors.

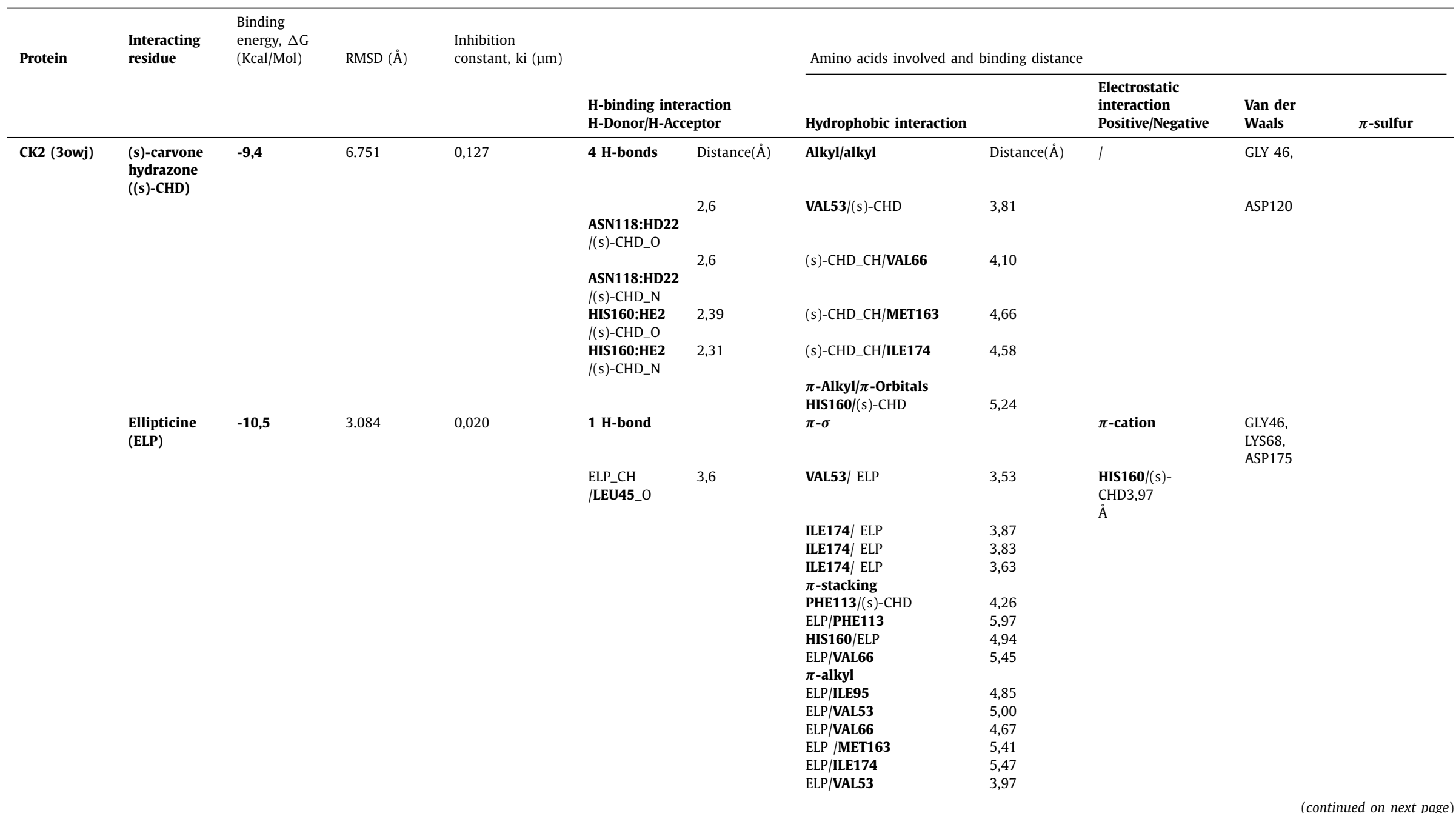


Table 3 (continued)

\begin{tabular}{|c|c|c|c|c|c|c|c|c|c|c|c|}
\hline \multirow[t]{2}{*}{ Protein } & \multirow{2}{*}{$\begin{array}{l}\text { Interacting } \\
\text { residue }\end{array}$} & \multirow{2}{*}{$\begin{array}{l}\text { Binding } \\
\text { energy, } \Delta G \\
\text { (Kcal/Mol) }\end{array}$} & \multirow[t]{2}{*}{$\operatorname{RMSD}(\AA)$} & \multirow{2}{*}{$\begin{array}{l}\text { Inhibition } \\
\text { constant, ki }(\mu \mathrm{m})\end{array}$} & & & \multicolumn{5}{|c|}{ Amino acids involved and binding distance } \\
\hline & & & & & \multicolumn{2}{|c|}{$\begin{array}{l}\text { H-binding interaction } \\
\text { H-Donor/H-Acceptor }\end{array}$} & \multicolumn{2}{|l|}{ Hydrophobic interaction } & $\begin{array}{l}\text { Electrostatic } \\
\text { interaction } \\
\text { Positive/Negative }\end{array}$ & $\begin{array}{l}\text { Van der } \\
\text { Waals }\end{array}$ & $\pi$-sulfur \\
\hline \multirow[t]{18}{*}{ EGFK (1m17) } & $\begin{array}{l}\text { (s)-carvone } \\
\text { hydrazone } \\
\text { ((s)-CHD) }\end{array}$ & $-8,3$ & 7.795 & 0,812 & 3 H-bonds & & Alkyl & & Salt bridge & $\begin{array}{l}\text { MET742, } \\
\text { LEU742, } \\
\text { LEU764, } \\
\text { THR766, } \\
\text { GLU738, } \\
\text { ARG817, } \\
\text { ASN818, } \\
\text { THR830 }\end{array}$ & \\
\hline & & & & & $\begin{array}{l}\text { (s)-CHD_NH/ } \\
\text { ASP831:OD1 }\end{array}$ & 2,39 & VAL702/(s)-CHD & & & & \\
\hline & & & & & $\begin{array}{l}\text { (s)-CHD_NH / } \\
\text { ASP831: } \\
\text { OD1:B }\end{array}$ & 2,97 & ALA719/(s)-CHD & 4,79 & $\begin{array}{l}\text { (s)-CHD_NH } \\
\text { |ASP831 2,39 }\end{array}$ & & \\
\hline & & & & & $\begin{array}{l}\text { (s)-CHD_NH } \\
\text { |ASP831:OD2 }\end{array}$ & 2,13 & LYS721/(s)-CHD & 5,09 & $\begin{array}{l}\text { (s)-CHD_NH } \\
\text { /ASP831 2,97 }\end{array}$ & & \\
\hline & & & & & & & LEU820/(s)-CHD & 5,34 & & & \\
\hline & & & & & & & (s)-CHD_CH/VAL702 & 5,41 & & & \\
\hline & & & & & & & (s)-CHD_CH/LEU820 & 4,76 & & & \\
\hline & & & & & & & $\begin{array}{l}\pi \text {-alkyl } \\
\text { PHE699/(s)-CHD }\end{array}$ & 4,55 & & & \\
\hline & & & & & & & PREOT2/(3)-CHD & $4,94 \AA$ & & & \\
\hline & $\begin{array}{l}\text { Ellipticine } \\
\text { (ELP) }\end{array}$ & $-8,5$ & 3.245 & 0,579 & 2 H-bonds & & $\pi-\sigma$ & & & $\begin{array}{l}\text { ALA719, } \\
\text { GLU738, } \\
\text { THR766, } \\
\text { THR830 }\end{array}$ & $\begin{array}{l}\text { MET742 } \\
(5,12 \AA)\end{array}$ \\
\hline & & & & & $\begin{array}{l}\text { ELP_NH/ } \\
\text { ASP831s }\end{array}$ & 2,87 & VAL702/ELP & $3,89 \AA$ & & & \\
\hline & & & & & $\begin{array}{l}\text { ELP_NH/ } \\
\text { ASP831 }\end{array}$ & 2,75 & VAL702/ELP & $3,85 \AA$ & & & \\
\hline & & & & & & & $\begin{array}{l}\text { VAL702/ELP } \\
\pi \text {-alkyl }\end{array}$ & $3,96 \AA$ & & & \\
\hline & & & & & & & ELP/LYS721 & $4,96 \AA$ & & & \\
\hline & & & & & & & ELP/VAL702 & $4,94 \AA$ & & & \\
\hline & & & & & & & ELP/LYS721 & $5,06 \AA$ & & & \\
\hline & & & & & & & ELP/LEU820 & $5,47 \AA$ & & & \\
\hline & & & & & $\mathrm{s}$ & & ELP/LEU694 & $5,16 \AA$ & & & \\
\hline
\end{tabular}




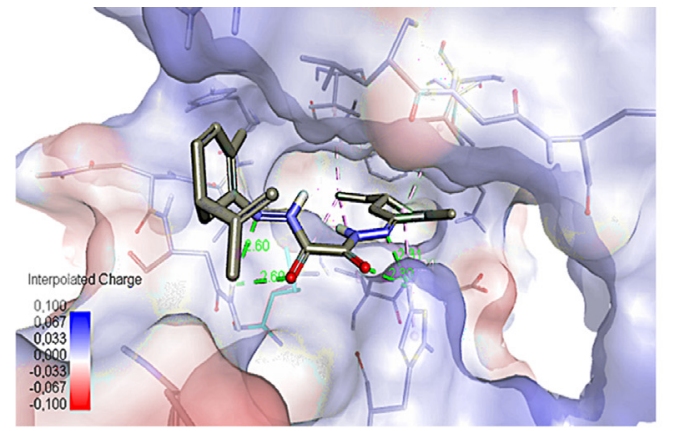

A:sp
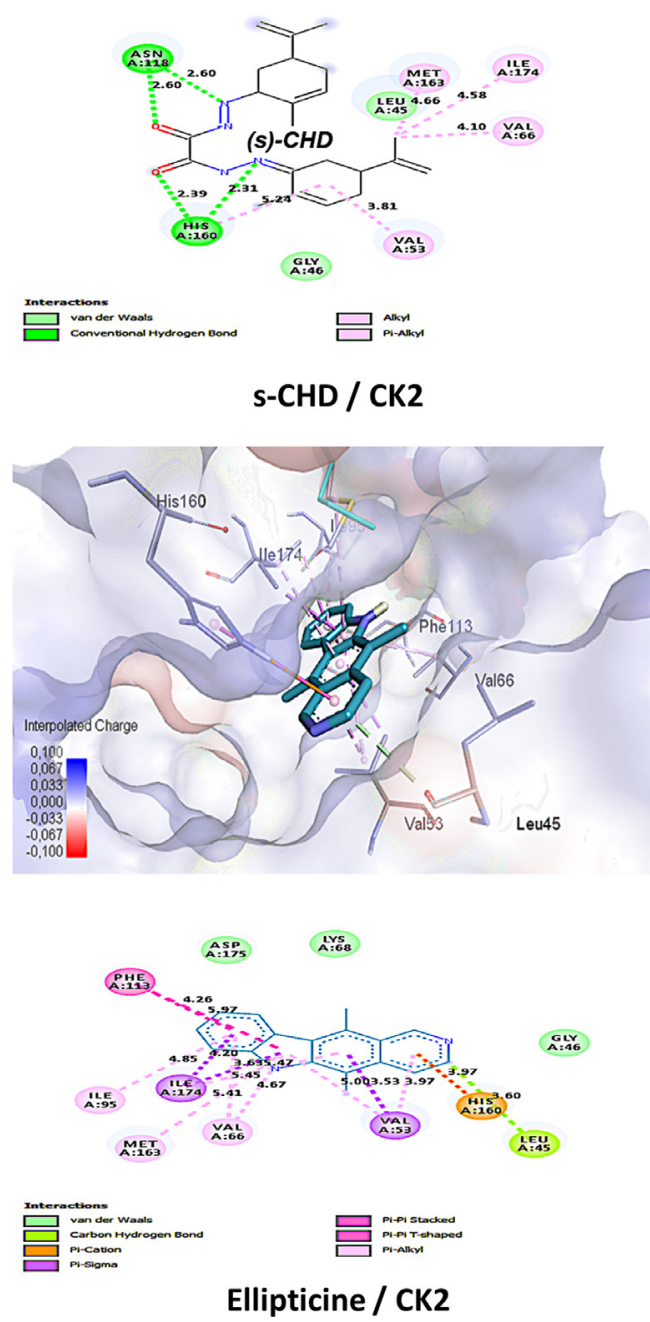
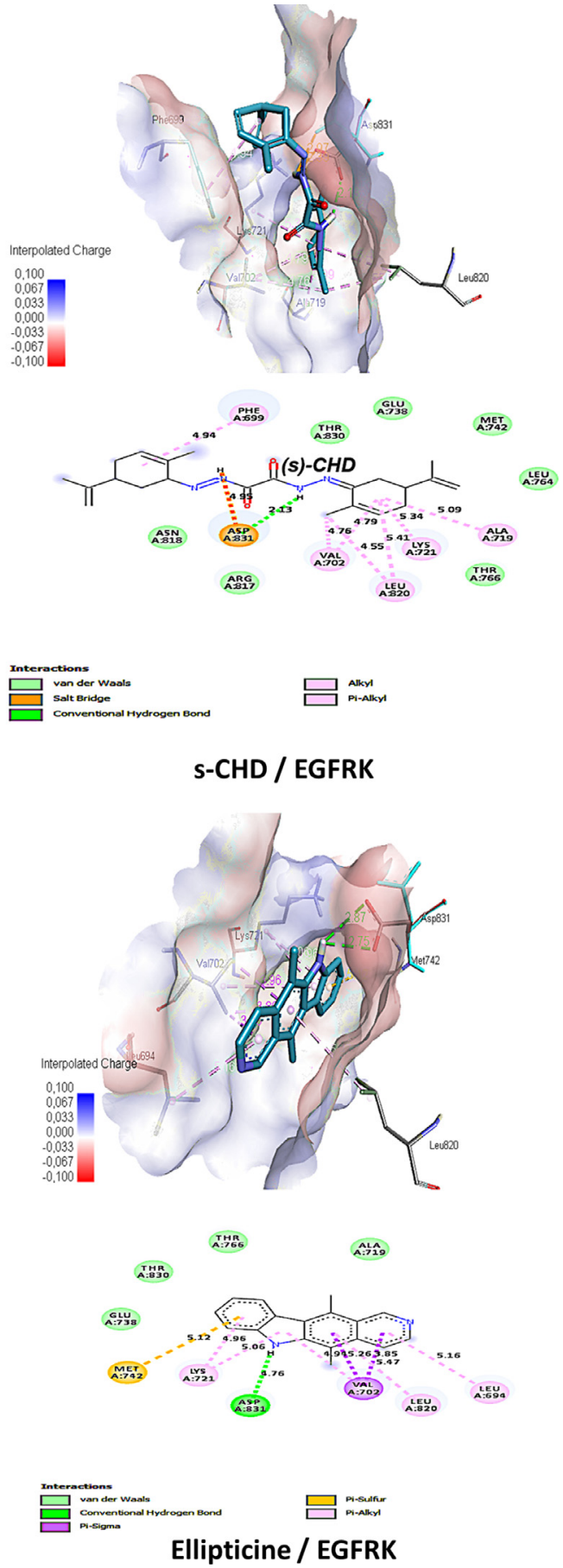

Fig. 4. Different orientations and a possible geometric permutation for hydrogen-bonding arrangements for the ligands/receptors binding pocket.

by interaction of the $\mathrm{NH}$ group of the carbazole moiety with oxygen atom of ASP831:OD1 (2.87 $\AA$ ) and ASP831:OD1:B $(2.75 \AA)$ with a binding energy of $-8.5 \mathrm{Kcal} / \mathrm{mol}$. It should be considered that (S)-CHD contains two connected nitrogen atoms, two connected carbonyl groups and $\mathrm{C}-\mathrm{N}$ double bonds that are conjugated with an electron pair. This structural configuration is mainly responsible of physico-chemical proprieties of the synthesized (S)-CHD. Both nitrogen atoms of the hydrazine group are nucleophilic and may exhibit considerable reactivity and different electronic interactions with the amino acids involved in the active pocket of the docked proteins, hence, ( $S$ )-CHD can be considered as an ATP- competitive CK2/EGFK inhibitor. For the EGFK, this inhibition is possible when the ligand poses are included in the forty amino acids from the carboxyl-terminal tail, that are distinguished in possessing constitutive kinase activity of ATP phosphorylation event within their kinase domains [46,47]. Herein, the (S)-CHD docking sites are found in close contact with the kinase domain where the interacted amino acids are involved between the EGFRK domain and carboxyl-terminal substrate.

The majority of subsequent biological studies have discussed the DNA topoisomerase and telomerase enzymes as particular targets for ellipticine being known for its topoisomerase inhibition 
pathway. However, ellipticine has largely been reported to have assorted molecular targets and its action was not only limited to DNA topoisomerase, it was even proved to inhibit other proteins involved in the tumor growth process, such as CK2 [32]. Accordingly, a comparative docking study of s-CHD and ellipticine was established on CK2 and EGFR to determine whether the two molecules may exhibit affinity for the same receptor site and to identify the nature of interactions. Current findings based on that theory were very promoting, since a close binding scores and similar linking sites were virtually found in the ATP binding pockets. The docking results, afforded valuable information for another possible inhibitor action of ellipticine, which is the EGFR kinases.

\section{Conclusions}

The present study relates to the hemi-synthesis of (S)-carvone hydrazone (S)-CHD as a novel symmetrical chiral ligand obtained from caraway essential oil which majorly contains the naturally occurring $(S)$-carvone. The reaction is performed via an imine bicondensation of oxalyldihydrazide (ODH) on the carbonyl group of $(S)$-carvone without any prior purification or isolation of this starting keto-terpene from its oil matrix. (S)-CHD was fully characterized by 2D-NMR spectroscopy and chiral LCMS analysis evidencing therefore, the formation of a single pure enantiomer. The crystal structure was further confirmed by using Single-crystal Xray diffraction Biologically, (S)-CHD does not affect normal cells viability but has an important cytotoxic potential against HepG2, Hela and MCF-7 tumor cell lines. The (S)-CHD docking studies have proved high affinity towards the kinase domain of the receptors CK2 and EGFRK, being able to bind to their kinase ATP region and induce their inhibition.

\section{Materials and methods}

\subsection{Chemicals and apparatus}

All the solvent and products were employed as received without further purification and were purchased from SigmaAldrich. Crystal structure refinement is performed using Singlecrystal X-ray diffraction (Benchtop X-Ray Diffractometer RIGAKU model MiniFlex II; transmission mode; Cu KR1 radiation (Gemonochromated)). Clevenger apparatus, Supercritical fluid extractor and Soxhlet are used for plan essential oil extraction. NMR spectra are recorded on a $400 \mathrm{MHz}$ Brüker (Avance III NMR. Spectrometer). LC-MS analysis was carried out in Agilent 1200 series/Agilent 6130B Single Quadrupole. Additionally, Chiral chromatographic separation was performed on LC Waters 600 multisolvents delivery system equipped to UV-vis detector.

\subsection{Plant material}

Dry seeds of $C$. carvi L. (around $5 \mathrm{Kg}$ ) were purchased from local selling point in Algiers -Algeria- during June 2019. Botanical authentication of the plant seeds was made by taxonomist at the National School of Agronomy-Algeria-. The collected biomass was ground to a fine powder ( $\sim 2 \mathrm{~mm}$ mesh size) using an electric using Bel-Art Micro-Mill Grinder with Timer; Stainless Steel Blade and Grinding Chamber; 115VAC, $60 \mathrm{~Hz}$ (H37252-0000) before extraction. After grinding, the samples were weighed then stored in sealed glass jars and kept at $4{ }^{\circ} \mathrm{C}\left( \pm 0.5^{\circ} \mathrm{C}\right)$.

\subsection{Essential oils extraction}

Caraway volatile compounds were extracted using three extraction methods. Hydrodistillation, Soxhlet (or Clevenger) extraction and Supercritical $\mathrm{CO}_{2}$ extraction.

\subsubsection{Hydrodistillation (HD)}

The HD method was established as previously reported [33]. Where an amount of $100 \mathrm{~g}$ of crushed plant samples was mixed with $500 \mathrm{ml}$ distillated water in $1 \mathrm{~L}$ flask and a closed Clevenger apparatus was mounted with condenser unit connected to WISECIRCU thermostat connected to Fisher Scientific Polystat 36 with a cooling capacity over the entire temperature to $-30{ }^{\circ} \mathrm{C}$. EOs extraction was processed in closed cycles at atmospheric pressure for $3 \mathrm{~h}$. After extraction, the volatile distillate was collected over anhydrous sodium sulfate and refrigerated at $4{ }^{\circ} \mathrm{C}$ prior to analysis.

\subsubsection{Soxhlet extraction (SE)}

A conventional solid-liquid extraction was performed by Soxhlet extractor (- $40 \mathrm{~mm}$ ID, with $250-\mathrm{mL}$ round bottom flask) using a constant ration of $1: 20(\mathrm{~m} / \mathrm{v})$ matrix/solvent according to the procedure described in the literature [22]. An amount (25 g) of grinded seed materials was placed in the thimble-holder and the extraction was performed with $200 \mathrm{~mL}$ of n-hexane (bp $68.5^{\circ} \mathrm{C}$ ) during many cycles for an interval time of $6 \mathrm{~h}$. After cooling, the trapped oil in the solvent was separated using rotary evaporator (Büchi R-210, Flawil, Switzerland) under vacuum at temperature of $45^{\circ} \mathrm{C}$.

\subsubsection{Supercritical $\mathrm{CO}_{2}$ extraction (SCF)}

SCF extraction was carried out using a laboratory-scale system (Speed-SFE) previously optimized according to the methodology developed by [21]. The extraction was carried out in a cylindrical extractor vessel $(500 \mathrm{~mL}$, length $35 \mathrm{~cm}$ and internal diameter $5 \mathrm{~cm}$ ) which was loaded a steel mesh filters on both end sides. The supercritical $\mathrm{CO}_{2}$ was passed continuously in current flow ( $4 \mathrm{ml} / \mathrm{min}$ ) for $2 \mathrm{~h}$ through the stationary bearing seeds (approximately $75 \mathrm{~g}$ of grinded seeds) at a temperature and pressure above the critical values. Experimentally, to ensure a better equilibrium distribution of volatile oil component between the seeds and the solvent and a good mass transfer rate of the oil from the seeds to the solvent, the temperature was set at $35{ }^{\circ} \mathrm{C}$ and the Pressure at 125 Bar. The $\mathrm{CO} 2$ can then be depressurized to atmospheric pressure and the extracts obtained were collected into a clean vial. The residual solvent was evaporated under vacuum to calculate the extraction yield then stored at $4{ }^{\circ} \mathrm{C}$ prior to analysis.

\subsection{GC-MS analysis of the EOS}

A GC-MS instrument (Konic, HRGC 4000B Gas Chromatograph equipped with auto-sampler and capillary injector). A volume of $1.0 \mu \mathrm{l}$ of Eos was injected into the GC equipped with an HB5MS column (30 m x 0,25 mmi.d, film thickness 0,25 $\mu \mathrm{m}$; HewlettPackard, 5\% Phenyl 95\% dimethylpolysiloxane stationary phase). The injector was set at $280^{\circ} \mathrm{C}$ and He (99,995\% purity) was used as carrier gas with a linear velocity of $1 \mathrm{ml} / \mathrm{min}$. GC-MS setting parameters were fixed using the following conditions: split flow $30 \mathrm{ml} / \mathrm{min}$; Initial oven temperature was $60{ }^{\circ} \mathrm{C}$ and holding time was $1 \mathrm{~min}$ : then progressed from 60 to $300{ }^{\circ} \mathrm{C}$ at $10{ }^{\circ} \mathrm{C} / \mathrm{min}$; oven run time was $26 \mathrm{~min}$; the ionization mode used with electronic impact at $70 \mathrm{eV}$. The compounds of the EOs were identified after injecting a mixture of alkanes $\left(\mathrm{C}_{6}-\mathrm{C}_{24}\right)$ under the same operating conditions by comparing their kovats index (KI) with those cited in the literature as well as with those of standards injected under the same conditions. Confirmation of the eluted compounds was based on the mass spectral of the fragmentation patterns using Wiley-8 and NIST-14 Database mass spectrometry libraries.

\subsection{General procedure for the (s)-carvone hydrazone synthesis}

Amount of ODH $(0.142 \mathrm{~g}, 1.2 \mathrm{mmol})$ was added to a mixture solution of ethanol and water (80/20) and let for 5 min under con- 
tinuous stirring. The caraway seed essential oil $(1 \mathrm{mmol}$ of $(S)$ carvone with a molar excess calculated on the basis of $60 \%$ of mass, approximately $0.26 \mathrm{ml}$ or $0.251 \mathrm{~g}$ of the crude oil) is added and the resulting mixture was brought to react at $80^{\circ} \mathrm{C}$ under reflux for $6 \mathrm{~h}$. The mixture was then cooled to $20{ }^{\circ} \mathrm{C}$ and filtered under vacuum. The precipitate was washed with pure ethanol and followed with ethylic ether to eliminate the remaining impurities of the starting crude material. The white crystal product is then air-dried, yielding the desired s-CHD compound $(0.207 \mathrm{~g}, 82.5 \%)$.

\subsection{Chemical characterization}

\subsubsection{Chiral HPLC and LCMS analysis}

Chromatographic characterization of the synthesized compound was performed by liquid chromatography-HPLC following the methodology described by [49]. The compound was prepared at a ratio of acetonitrile/water (70:30 v/v, HPLC-grade) and further filtered through a Whatman $0.45 \mu \mathrm{M}$ syringe filter. The equipment was a Waters 600 HPLC multi-solvent delivery system with a 225 $\mu \mathrm{L}$ pump head volume at $45 \mathrm{~mL} / \mathrm{min}$ flow rate and auto-sampler (Marshall Scientific, Milford, USA) equipped with UV-Vis and refractive index detector (Marshall Scientific, Milford, USA). The analysis was achieved in isocratic elution mode on a C18 reserve phase column $(30 \mathrm{~mm} \times 4.6 \mathrm{~mm} \times 5 \mu \mathrm{m}$, Discovery columns, Merck, Germany) at a flow rate of $1.0 \mathrm{ml} / \mathrm{min}$ and wavelength at $254 \mathrm{~nm}$ an injection of $20 \mu \mathrm{l}$. additionally, the high performance liquid chromatography coupled to a mass spectrometer was carried out in Agilent 1200 Series with binary pump and MS Agilent 6130 (Agilent Technologies, USA) single quadrupole with an electrospray ionization (ESI) source were recorded in negative and positive modes. The identifications were performed in the same previous conditions at a flow rate of $0.4 \mathrm{ml} / \mathrm{min}$. Furthermore, the enantiomer separation of essential oil and sample analysis were determined using chiral column type CHIRALPAK® IB (Chiral Technologies Europe, Illkirch, France) stationary phase cellulosetris(3,5-dimethylphenylcarbamate) immobilized on $5 \mu \mathrm{m}$ silica-gel, $250 \mathrm{~mm} \times 4.6 \mathrm{~mm}$ ID). The mobile phase used was hexane/ isopropanol (isocratic mode, 60:40, (v/v)) at a flow rate of $0.5 \mathrm{ml} / \mathrm{min}$ ranging in wavelength from $190 \mathrm{~nm}$ to $400 \mathrm{~nm}$ an injection of $5 \mu$ l.

\subsubsection{NMR spectroscopy analysis}

${ }^{1} \mathrm{H},{ }^{13} \mathrm{C}$ and 2D NMR spectra were recorded at $298 \mathrm{~K}$ on Bruker AV III 400 MHZ Spectrometer using tetramethylsilane (TMS) as an internal reference. The synthesized compound was dissolved in $\mathrm{CDCl}_{3}$ for the analysis. The chemical shifts were expressed on the scale of ppm and were referenced to residual $\mathrm{CHCl}_{3}$ at $\delta 7.26$ for proton and $\delta 77.0$ for carbon. Unequivocal ${ }^{13} \mathrm{C}$ assignments were made with the aid of 2D gHSQC and gHMBC experiment. Contrary to crude oil and limonene were characterized in DMSO-d6 solvent and referenced at $\delta 2.50\left(\delta 3.33 \mathrm{H}_{2} \mathrm{O}\right)$ for proton and $\delta 39.52$ for carbon. Coupling constants $(\mathrm{J})$ are reported in hertz $(\mathrm{Hz})$. The terms $\mathrm{s}, \mathrm{d}, \mathrm{m}$ refer to singlet, doublet and multiplet, respectively.

Compound S-CHD: N'1,N'2-bis((S,Z)-2-methyl-5-(prop-1-en2-yl)cyclohex-2-en-1-ylidene)oxalohydrazide, $\mathrm{C}_{22} \mathrm{H}_{30} \mathrm{~N}_{4} \mathrm{O}_{2}$ : (MW: $382.51 \mathrm{~g} / \mathrm{mol}$, white crystals, 82.5 yield, $\left.\mathrm{mp}=184-185{ }^{\circ} \mathrm{C}\right) .{ }^{1} \mathrm{H}$ NMR (DMSO-d $6,400 \mathrm{MHz}): \delta 1.56-1.90\left(\mathrm{~s}, 12 \mathrm{H}, \mathrm{CH}_{3}\right), 2.00$ - $2.42\left(\mathrm{~m}, 8 \mathrm{H}, \mathrm{CH}_{2}\right), 2.79-2.90(\mathrm{~m}, 1 \mathrm{H}, \mathrm{CH}), 4.74-4.83(\mathrm{~d}$, $J=11.7 \mathrm{~Hz}, 4 \mathrm{H}, \mathrm{C}=\mathrm{CH}_{2}$ extracyclic), $6.00-6.40(2 \mathrm{H}, \mathrm{m}, \mathrm{C}=\mathrm{CH}$ intracyclic), 10.39 and $11.00(2 \mathrm{~s}, \mathrm{NH}) \mathrm{ppm} .{ }^{13} \mathrm{C}$ NMR (DMSO- $\mathrm{d}_{6}$, $100 \mathrm{MHz}): 17.73,18.14,20.90$ and $21.20\left(\mathrm{CH}_{3}\right), 29.60$ and 29.86 $(\mathrm{CH}), 30.26$ and $30.37\left(\mathrm{CH}_{2}\right), 110.43$ and $110.70\left(\mathrm{C}=\mathrm{CH}_{2}\right.$ extracyclic $)$, 132.29 ( $\mathrm{C}=\mathrm{CH}_{2}$ extracyclic), 132.54 and 136.21 ( $\mathrm{C}=\mathrm{CH}$ intracyclic), 147.85 and 147.95 ( $C=\mathrm{CH}$ intracyclic), $157.46(\mathrm{NH}-\mathrm{C}=0), 160.18$ $(\mathrm{NH}-\mathrm{N}=C)$ ppm. MS ESI ${ }^{+} \mathrm{C}_{22} \mathrm{H}_{30} \mathrm{~N}_{4} \mathrm{O}_{2}(M+H) \mathrm{m} / z$ $383.2(100 \%)$, Exact Mass: 382.24. Elemental Analysis calculated C, 69.08; H, 7.91;
$\mathrm{N}, 14.65$, found: C: $66.47 \%$; $\mathrm{H}$ 7.62; N: 15.67\%. Optical rotation: $+103.25^{\circ}$

\subsubsection{X-Ray powder diffraction (XRDP) measurements}

The samples were carried out on a Benchtop X-Ray Diffractometer RIGAKU model MiniFlex II equipped with copper that was used as the source of the X-ray tube in a scanning range of $3-145^{\circ}(2 \theta)$, scanning speed $0,01-100^{\circ} / \mathrm{min}(2 \theta)$ and a minimum step width $0,01^{\circ}(2 \theta)$. A sufficient amount of synthesized compound was supplied to cover $2 \mathrm{~cm}^{2}$ of the sample plate.

\subsection{Bioactivity assays}

\subsubsection{PrestoBlue ${ }^{\mathrm{TM}}$ cell viability assay}

Cell viability assay was evaluated on fibroblast cells model (L929) exposed to a different molar concentration of ( $s$ )-CHD aqueous solutions $(0.7$, to $100 \mu \mathrm{M})$ following the methodology of [50]. Two independent viability tests were monitored for $24 \mathrm{~h}$ and the results were expressed in percentage (\%). Living cells quantification was determined by PrestoBlue ${ }^{\mathrm{TM}}(\mathrm{PB})$ reagent used as cell viability indicator that became highly red-fluorescent dye by the reducing environment within viable cells. The color change can be detected fluorometrically (excitation 544-nm and emission 590-nm) using an automated microplate fluorometer (SerColab System).

\subsubsection{Antiproliferative assay}

Cytotoxicity of the (s)-CHD was evaluated by antigrowth effect on tumoral cells according to the procedure described by [51]. Four human tumor cell lines, NCI-H460 (non-small cell lung cancer), Hela (cervical carcinoma), HepG2 (hepatocellular carcinoma), MCF7 (breast carciroma) were selected for the assays. The cells were grown under standard cell culture conditions to be sub-cultured in 96-well plates at a density of $1.0 \times 10^{4}$ cells/well for the analysis. The Sulforhodamine B colorimetric assay was used to determine the cells growth inhibition exposed to a range of (s)-CHD concentrations serially diluted in ultrapure water starting from $8 \mathrm{mg} / \mathrm{mL}$. Likewise, the hepatotoxicity was conducted using a primary culture of non-tumor liver cells (PLP2). Ellipticine was used as positive control and the final results were presented in GI50 values (concentration that inhibited $50 \%$ of the cell growth).

\subsubsection{Anti-inflammatory activity}

For the anti-inflammatory assay was performed in-vitro using a cell-based model of lipopolysaccharide (LPS)-stimulated (RAW 264.7) murine macrophage-like cell line as previously described [51]. The assay is able to determine the anti-inflammatory activity of the produced molecule at different concentrations (serially diluted in ultrapure water starting from $400 \mu \mathrm{g} / \mathrm{mL}$ ) basing on measurement of NO levels produced by the stimulated RAW 264.7 cells. The response to a fixed dose of LPS is verified spectrophotometrically $(515 \mathrm{~nm})$ with nitrite NO levels measuring using the Griess reagent system kit and the results were expressed as IC50 values, corresponding to the sample concentration giving $50 \%$ of NO production inhibition. Dexamethasone (Thermo Fisher Scientific Co., Waltham, MA, USA) used as a positive control.

\subsection{In silico molecular docking}

A crystalized structure of human protein kinase CK2 (PDB entry: 3owj) and human Epidermal growth factor protein kinase domain EGFRK (PDB entry: $1 \mathrm{~m} 17$ ) was selected and obtained from the Protein Data Bank (https://www.rcsb.org/structure/30WJ and https://www.rcsb.org/structure/1M17). The receptor proteins (3owj and $1 \mathrm{~m} 17$ ) were first prepared for molecular docking by removing present ligand heteroatoms and water molecules using protein visualization UCSF chemira 1.14 software (U. of California, USA), 
and by addition of polar hydrogens followed by Kollman charges adjustment on AutoDock tools 1.5.7 software (ADT, The Scripps Research Institute, La Jolla, CA, USA). The set files of the receptors was saved as protein.pdbqt. MarvenSketch Software was used for chemical drawing and 3D.pdb graphics of the ligand (s)-CHD that was further prepared for molecular docking simulation by setting the torsion tree and rotatable, nonrotatable, as well as unrotatable bonds present in the ligand through AutoDock tools software then the obtained file was saved as ligand.pdbqt. The binding site of the receptor proteins is identified by using various protein visualization software such as PyMol 2.1 and Biovia DS visualizer according to the indications previously reported by the literature $[32,48]$. An appropriate grid box was set by running Autogrid utility of the AutoDock suite to cover all the macromolecular residues involved in the binding of the ligand as indicated in Table S19 in the Supporting Information. The grid dimensions enumerate the $x, y, z$ points of the grid box required to perform the molecular docking simulation of the receptors and saved as config.txt file to be processed by Autodock vina [52] to further set up the scoring function and binding sites. The PyMOL software 2.1.0 (Schrödinger Co., New York, NY, USA) was used for docking conformation analysis while the DS visualizer Software was used for 3D docking figures, calculations of interactions sites and distances and to build 2D graphics for visualization/interpretation of the receptor amino acids/ligand interaction. The molecular docking affinity of the receptors/ligand is validated basing on the obtained binding energy $(\Delta G)$ that should be ranging from -5 to $-15 \mathrm{kcal} / \mathrm{mol}$, on the values of RMSD $(\AA)$, predicted inhibition constant $(\mathrm{Ki})$ and interaction types and distances $(\AA)$. The $\Delta G$ of the small molecules with macromolecular targets is predicted by using the semiempirical force field. All the results obtained by molecular docking simulation were evaluated on the basis of hydrophilic and hydrophobic interactions obtained between the binding residues present in the active ligand binding site of the macromolecule and the ligand.

\section{Credit author statement}

O.T. conceptualized the whole work; R.T. performed the all extractions and synthetic experimental work and wrote the original draft preparation; L.B. and L.B. participated in the synthetic experimental work and optical rotation measurement; T.C and R.V collaborated in experimental work; I.F performed the biologic experiments; B.Z performed molecular docking studies and co-writingreview and editing the manuscript; A.H, K.B, R.C and A.S guidance and supervisions. All authors have read and approved to the published version of the final manuscript.

\section{Author contributions}

O.T. conceptualized the whole work; R.T. performed the all extractions and synthetic experimental work and wrote the original draft preparation; L.B. participated in the synthetic experimental work; T.C and R.V collaborated in experimental work; I.F performed the biologic experiments; B.Z performed molecular docking studies and co-writing-review and editing the manuscript; A.H and O.T guidance and supervisions. All authors have read and approved to the published version of the final manuscript.

\section{Declaration of Competing Interest}

The authors declare no conflict of interest.

\section{Supplementary materials}

Supporting information associated with this article (Full experimental details on GC-MS, MS, NMR, Chiral HPLC and Single-crystal $\mathrm{X}$-ray data) can be found in the online version.

\section{Declaration of Competing Interest}

The authors declare that they have no known competing financial interests or personal relationships that could have appeared to influence the work reported in this paper.

\section{Acknowledgements}

Thanks are due to the Research Center Scientific and Technical in Analyzes Physico-Chimiques CRAPC Algerian Directorate for research DGRSDT for the financial support. The authors thanks Fundação para a Ciência e a Tecnologia (FC\&T, Lisbon) for financial support through projects PTDC/MEC-ONC/29327/2017 and PTDC/EQU-EQU/ 32473/2017. We are thankful to NOVA University of Lisbon (FCT/UNL) for the financial support from Erasmus+ EU international credit mobility 2017-2019.the laboratory for Green Chemistry LAQV-REQUIMTE FCT/MCTES (UID/ QUI/ 50006/ 2019) is co-financed by the ERDF and the chemistry department for providing the instruments support.

\section{Supplementary materials}

Supplementary material associated with this article can be found, in the online version, at doi:10.1016/j.molstruc.2021.131220.

\section{References}

[1] K. Wagner, I. Elmadfa, Biological Relevance of Terpenoids: overview Focusing on Mono-, Di- and Tetraterpenes, Ann. Nutr. Metab. 47 (2003) 95-106, doi:10. $1159 / 000070030$

[2] J.F.Q. Moral del, A. Pérez, A.F. Barrero, Chemical synthesis of terpenoids with participation of cyclizations plus rearrangements of carbocations : a current overview, Phytochem Rev 19 (2020) 559-576, doi:10.1007/ s11101-019-09646-8.

[3] D.J. Jansen, A.,.S. Ryan, Synthesis of medicinally relevant terpenes: reducing the cost and time of drug discovery, Future Med. Chem. 6 (2014) 1127-1146.

[4] Christian Starkenmann, I. Cayeux, R. Brauchli, F Mayenzet, Hemisynthesis of Dihydroumbellulols from Umbellulone : new Cooling Compounds, J. Agric. Food Chem. 59 (2011) 677-683, doi:10.1021/jf103989j.

[5] F. Fongang, S. Yannick, J.J. Bankeu Kezetas, Terpenoids as Important Bioactive Constituents of Essential Oils, in: Essential Oils - Bioactive Compounds, New Perspectives and Applications phenylpropanoids, intechOpen, 2020, pp. 1-32.

[6] , 12, EFSA Scientific Opinion on the safety assessment of carvone, considering all sources of exposure, 2014

[7] Postal, C. Synthesis of (R) - (-) -Carvone Derivatives. 2010, 1381-1383.

[8] K.K. Aggarwal, S.P.S. Khanuja, A. Ahmad, V.K. Gupta, S. Kumar, Antimicrobial activity profiles of the two enantiomers of limonene and carvone isolated from the oils of Mentha spicata and Anethum sowa, Flavour Fragr. J. 17 (2002) 5963, doi:10.1002/ffj.1040.

[9] F.P. Nogoceke, I.M.R. Barcaro, D.P. de Sousa, R. Andreatini, Antimanic-like effects of (R)-(-)-carvone and (S)-(+)-carvone in mice, Neurosci. Lett. 619 (2016) 43-48, doi:10.1016/j.neulet.2016.03.013.

[10] S.M. Sabir, D. Singh, J.B.T Rocha, Vitro Antioxidant Activity of S-Carvone Isolated from Zanthoxylum alatum, Pharm. Chem. J. 49 (2015) 187-191, doi:10. 1007/s11094-015-1251-7.

[11] S. Clarke, Families of compounds that occur in essential oils, in: Essential Chemistry for Aromatherapy, 2008, pp. 41-77.

[12] Z.T. Najaran, M.K. Hassanzadeh, M. Nasery, S.A.Dill Emami, (Anethum graveolens L.) oils, in: Essential Oils in Food Preservation, Flavor and Safety, Elsevier Inc., 2016, pp. 405-412. ISBN 9780124166448.

[13] B. Sayed Ahmed, T. Talou, Z. Saad, A. Hijazi, M. Cerny, H. Kanaan, A. Chokr, O. Merah, Fennel oil and by-products seed characterization and their potential applications, Ind. Crop. Prod. 111 (2018) 92-98, doi:10.1016/j.indcrop.2017.10. 008.

[14] S. Baananou, E. Bagdonaite, B. Marongiu, A. Piras, S. Porcedda, D. Falconieri, N. Boughattas, Extraction of the volatile oil from Carum carvi of Tunisia and Lithuania by supercritical carbon dioxide: chemical composition and antiulcerogenic activity, Nat. Prod. Res. 27 (2013) 2132-2136, doi:10.1080/14786419. 2013.771350.

[15] I.J. Moro, G.D.G.A. Gondo, E.G. Pierri, R.C.L.R. Pietro, C.P. Soares, D.P. de Sousa, A.G. dos Santos, Evaluation of antimicrobial, cytotoxic and chemopreventive activities of carvone and its derivatives, Brazilian J. Pharm. Sci. 53 (2017) 1-8, doi:10.1590/s2175-97902017000400076.

[16] H. Barkai, S. El Abed, A. El Aabedy, S. Guissi, S. Ibnsouda Koraichi, Antifungal Activities of B-Ionone, Carvone and 1,8-Cineole Essential Oil Components Against Aspergillus niger Spores, J. Chem. Pharm. Res. 9 (2017) 52-56.

[17] E.A. Alasmari, A.S. Mehanna, Cytotoxic effects of S-(+)-Carvone on selected human cancer cell lines, J. Anal. Pharm. Res. 8 (2019) 149-158, doi:10.15406/japlr. 2019.08.00330. 
[18] E. Aydın, H. Türkez, M.S. Keleş, Potential anticancer activity of carvone in N2a neuroblastoma cell line, Toxicol. Ind. Health 31 (2015) 764-772, doi:10.1177| 0748233713484660.

[19] A. Raal, E. Arak, A. Oravb, The content and composition of the essential oil Found in Carum carvi L. commercial fruits obtained from different countries, J. Essent. Oil Res. 24 (2012) 53-59, doi:10.1080/10412905.2012.646016.

[20] M.N. Abdalaziz, M. Mohamed Ali, M. Dafallah Gahallah, M.I. Garbi, A.S. Kabbashi, Evaluation of Fixed Oil, Seed Extracts, of Carum carvi L, Int. J. Comput. Theor. Chem. 5 (2017) 1-8, doi:10.11648/j.ijctc.20170501.11.

[21] T. Baysal, D.A.J. Starmans, Supercritical carbon dioxide extraction of carvone and limonene from caraway seed, J. Supercrit. Fluids 14 (1999) 225-234, doi:10.1016/S0896-8446(98)00099-0.

[22] S. Chemat, H. Aït-Amar, A. Lagha, D.C. Esveld, Microwave-assisted extraction kinetics of terpenes from caraway seeds, Chem. Eng. Process. Process Intensif. 44 (2005) 1320-1326, doi:10.1016/j.cep.2005.03.011.

[23] D.P. De Sousa, Preface, Bioact. Essent. Oils Cancer (2015) ix-x, doi:10.1007/ 978-3-319-19144-7.

[24] A.A. Verstegen-Haaksma, H.J. Swarts, B.J.M. Jansen, A. de Groot, N. BottemaMacGillavry, B. Witholt, Application of S-(+)-carvone in the synthesis of biologically active natural products using chemical transformations and bioconversions, Ind. Crops Prod. 4 (1995) 15-21, doi:10.1016/0926-6690(95)00006-X.

[25] P. Xu, W. Li, J. Xie, C. Zhu, Exploration of C-H Transformations of Aldehyde Hydrazones: radical Strategies and beyond, Acc. Chem. Res. 51 (2018) 484-495, doi:10.1021/acs.accounts.7b00565.

[26] M. Khalfaoui, C. Farid, B.E.C. Ziani, N. Bennamane, B. Cherfaoui, W. Frites, M. Valega, R.F. Mendes, F.A.A. Paz, R. Chebout, et al., Hemi-synthesis, invitro and in-silico bioactivities of new chiral-Schiff bases and benzodiazepine derivatives from Ammodaucus leucotrichus(S)-perillaldehyde, J. Mol. Struct. 1241 (2021) 130690, doi:10.1016/j.molstruc.2021.130690.

[27] D.E. Lewis, Modern adaptations of the Wolff-Kishner reduction, in: The Wolff-Kishner Reduction and Related Reactions, Elsevier Inc., 2019, pp. 133-167. ISBN 9780128157275

[28] M.S. More, P.G. Joshi, Y.K. Mishra, P.K. Khanna, Metal complexes driven from Schiff bases and semicarbazones for biomedical and allied applications: a review, Mater. Today Chem. 14 (2019) 100195, doi:10.1016/j.mtchem.2019. 100195.

[29] Adam, M.S.S.; Mohamad, A.D.M.; El-Hady, O.M. Synthesis and characterization of novel bis(diphenylphosphino)-oxalyl and (substituted) malonyl dihydrazones: p,N,N,P-tetradentate complexes of an oxalyl derivative with $\mathrm{Cu}(\mathrm{II}), \mathrm{Pd}(\mathrm{II})$, and $\mathrm{Mn}(\mathrm{II})$. Monatshefte fur Chemie2014, 145, 435-445, doi:10.1007/s00706-013-1122-4.

[30] S. Rollas, S.G. Küçükgüzel, Biological activities of hydrazone derivatives, Molecules 12 (2007) 1910-1939, doi:10.3390/12081910.

[31] W.W. Wardakhan, N.N.E. El-Sayed, R.M. Mohareb, Synthesis and anti-tumor evaluation of novel hydrazide and hydrazide-hydrazone derivatives, Acta Pharm 63 (2013) 45-57, doi:10.2478/acph-2013-0004.

[32] R. Prudent, V. Moucadel, C.H. Nguyen, C. Barette, F. Schmidt, J.C. Florent, L. Lafanechère, C.F. Sautel, E. Duchemin-Pelletier, E. Spreux, et al., Antitumor activity of pyridocarbazole and benzopyridoindole derivatives that inhibit protein kinase CK2, Cancer Res. 70 (2010) 9865-9874, doi:10.1158/0008-5472. CAN-10-0917.

[33] K. Assami, D. Pingret, S. Chemat, B.Y Meklati, F. Chemat, Ultrasound induced intensification and selective extraction of essential oil from Carum carvi $\mathrm{L}$. seeds, Chem. Eng. Process. Process Intensif. 62 (2012) 99-105, doi:10.1016/j. cep.2012.09.003.

[34] Z. Hagos, A. Mulugeta, G.V. K., K. Chaithanya, K., N B., Chemical Composition and Physicochemical Properties of Essential Oil from Myrtus communis, Int. J. Pharm. Clin. Res. 9 (2017) 439-443, doi:10.25258/ijpcr.v9i6.8772.

[35] É. Lemberkovics, Á. Kéry, A. Kakasy, É. Szoke, B. Simándi, Effect of extraction methods on the composition of essential oils, Acta Hortic. 597 (2004) 49-56, doi:10.17660/ActaHortic.2003.597.4.
[36] F. Chemat, M. Abert Vian, A.S. Fabiano-Tixier, M. Nutrizio, A. Režek Jambrak, P.E.S. Munekata, J.M. Lorenzo, F.J. Barba, A. Binello, G. Cravotto, A review of sustainable and intensified techniques for extraction of food and natural products, Green Chem. 22 (2020) 2325-2353, doi:10.1039/c9gc03878g.

[37] S.D. Manjare, K. Dhingra, Supercritical fluids in separation and purification: a review, Mater. Sci. Energy Technol. 2 (2019) 463-484, doi:10.1016/j.mset.2019. 04.005.

[38] A.L Spek, PLATON SQUEEZE: a tool for the calculation of the disordered solvent contribution to the calculated structure factors, Acta Crystallogr. Sect. C Struct. Chem. 71 (2015) 9-18, doi:10.1107/S2053229614024929.

[39] C.F. Macrae, P.R. Edgington, P. McCabe, E. Pidcock, G.P. Shields, R. Taylor, M. Towler, J. Van De Streek, Mercury: visualization and analysis of crystal structures, J. Appl. Crystallogr. 39 (2006) 453-457, doi:10.1107| S002188980600731X.

[40] T.L. Riss, R.A. Moravec, A.L. Niles, S. Duellman, H.A. Benink, T.J. Worzella, L. Minor, Cell Viability Assays, Assay Guid. Man (2016) 1-25.

[41] H.M.E. Tehrani, M. Kamaleddin EsfahaniZadeh, V. Mashayekhi, M. Hashemi, F. Kobarfard, F. Gharebaghi, S. Mohebbi, Synthesis, antiplatelet activity and cytotoxicity assessment of indole-based hydrazone derivatives, Iran. J. Pharm. Res. 14 (2015) 1077-1086, doi:10.22037/ijpr.2015.1739.

[42] H. Ji, J. Wang, H. Nika, D. Hawke, S. Keezer, Q. Ge, X. Fang, D.W. Litchfield, K. Aldape, Z. Lu, EGF-induced ERK activation promotes CK2-mediated disassociation of $\alpha$-catenin from $\beta$-catenin and transactivation of $\beta$-catenin, Mol. Cell 36 (2009) 547-559 EGF-induced, doi:10.1016/j.molcel.2009.09.034.

[43] Y. Zheng, B.C. McFarland, D. Drygin, H. Yu, S.L. Bellis, H. Kim, M. Bredel, E.N. Benveniste, Targeting protein kinase CK2 suppresses prosurvival signaling pathways and growth of glioblastoma, Clin. Cancer Res. 19 (2013) 6484-6494 doi:10.1158/1078-0432.CCR-13-0265.

[44] U. Golla, A. Adhikary, A.K. Mondal, R.S. Tomar, S. Konar, Synthesis, structure, magnetic and biological activity studies of bis-hydrazone derived $\mathrm{Cu}(\mathrm{II})$ and Co(II) coordination compounds, Dalt. Trans. 45 (2016) 11849-11863, doi:10. 1039/c6dt01496h.

[45] P.J. Murray, J.E. Allen, S.K. Biswas, E.A. Fisher, D.W. Gilroy, S. Goerdt, S. Gordon, J.A. Hamilton, L.B. Ivashkiv, T. Lawrence, et al., Macrophage activation and polarization: nomenclature and experimental guidelines, Immunity 41 (2014) 14-20, doi:10.1016/j.immuni.2014.06.008.

[46] N. Jura, X. Zhang, N.F. Endres, M.A. Seeliger, T. Schindler, O. Kuriyan, Catalytic control in the EGF Receptor and its connection to general kinase regulatory mechanisms, Mol. Cell 42 (2011) 9-22 Catalytic, doi:10.1016/j.molcel.2011.03. 004.

[47] N. Lee, J.G. Koland, Conformational changes accompany phosphorylation of the epidermal growth factor receptor C-terminal domain, Protein Sci. 14 (2005) 2793-2803, doi:10.1110/ps.051630305.Signaling.

[48] J. Stamos, M.X. Sliwkowski, C. Eigenbrot, Structure of the epidermal growth factor receptor kinase domain alone and in complex with a 4anilinoquinazoline inhibitor, J. Biol. Chem. 277 (2002) 46265-46272, doi:10. 1074/jbc.M207135200.

[49] L. Zhang, J. Cao, L. Hao, C. Kang, Quality Evaluation of Lepidium meyenii (Maca) Based on HPLC and LC-MS Analysis of its Glucosinolates from Roots, Food Anal. Methods 10 (2017) 2143-2151, doi:10.1007/s12161-016-0787-9.

[50] M. Sonnaert, I. Papantoniou, F.P. Luyten, J. Schrooten, Quantitative Validation of the Presto BlueTM metabolic assay for online monitoring of cell proliferation in a 3d perfusion bioreactor system, Tissue Eng. - Part C 21 (2015) 519-529, doi: 10.1089/ten.tec.2014.0255.

[51] B.E.C. Ziani, M. Carocho, R.M.V. Abreu, K. Bachari, M.J. Alves, R.C. Calhelha, O. Talhi, L. Barros, I.C.F.R. Ferreira, Phenolic profiling, biological activities and in silico studies of Acacia tortilis (Forssk.) Hayne ssp. raddiana extracts, Food Biosci. 36 (2020) 100616, doi:10.1016/j.fbio.2020.100616.

[52] O. Trott, A.J. Olson, AutoDock Vina: improving the speed and accuracy of docking with a new scoring function, efficient optimization, and multithreading, J. Comput. Chem. 31 (2009) NA-NA, doi:10.1002/jcc.21334. 